\title{
O euro e as relações exteriores da União Européia
}

\section{DEISY VENTURA* e PHILIPPE ALQUIÉ**}

A União européia lançou-se numa experiência cujo resultado, seja positivo ou negativo, é referência indispensável na discussão das futuras relações econômicas internacionais. A gestão da política monetária, importante elemento da soberania nacional, foi transferida ao domínio comunitário por onze entre os quinze Estados membros da União Européia, constituindo uma União Econômica e Monetária (UEM). O fator mais visível desta competência partilhada é a moeda única, o euro. Todavia, a UEM constitui a maior extensão do poder comunitário vista até o momento e enseja um debate que ultrapassa largamente as dificuldades intra-bloco, como os polêmicos critérios impostos para que um Estado pudesse ser aceito na zona euro ou as dificuldades práticas de implementação da moeda num grande e heterogêneo território.

Para gerir a política monetária e coordenar a política econômica da UEM, o Tratado de Maastricht associou novos órgãos às já consolidadas instituições da Comunidade européia (Conselho de Ministros, Comissão européia, Parlamento europeu e Corte de Justiça). Criou-se o Sistema Europeu de Bancos Centrais (SEBC), constituído de um Banco Central Europeu e dos Bancos Centrais Nacionais. A dinâmica desta estrutura original modificará as relações financeiras e monetárias internacionais mas atingirá, igualmente, a política exterior lato sensu. Dita constatação é consensual por diversas razões. No âmbito deste artigo, cabe apenas lembrar que a Europa tem diante de si a possibilidade de recuperar o papel destacado que desempenhou outrora como fornecedor de capitais. Sua nova moeda promete ocupar um espaço importante no comércio mundial, alterando substancialmente a atual conjuntura, esboçada na seguinte tabela. 


\section{Tabela 1}

\section{O atual desempenho internacional do dólar, do yen e das moedas européias}

\begin{tabular}{|l|c|c|c|c|}
\hline Part. em \% no: & Dólar & Yen & $\begin{array}{c}\text { Marco } \\
\text { alemão }\end{array}$ & $\begin{array}{c}\text { Outras moedas } \\
\text { européias (a) }\end{array}$ \\
\hline no comércio mundial realizado & 47.6 & 4.8 & 15.3 & 18.2 \\
\hline $\begin{array}{l}\text { nas transações de câmbio (sobre um } \\
\text { total de 200\%) }\end{array}$ & 83.8 & 23.6 & 37.1 & 32.8 \\
\hline $\begin{array}{l}\text { nas emissões de obrigações } \\
\text { internacionais }\end{array}$ & 37.8 & 17.7 & 15.6 & 8.8 \\
\hline $\begin{array}{l}\text { na divida dos países em } \\
\text { desenvolvimento }\end{array}$ & 50.0 & 18.1 & 16.1 & \\
\hline nas reservas oficiais mundiais & 56.4 & 7.1 & 13.7 & 12.1 \\
\hline
\end{tabular}

(a) Composição exata variável segundo as rubricas, mas que inclui sempre a libra esterlina, o franco francês, o florin e o ECU.

Fonte: La lettre du CEPII, n 156, abril 1997

Uma construção sui generis como a UEM ocasiona a discussão do funcionamento do sistema financeiro internacional em si mesmo. Esta necessidade objetiva soma-se à antiga idéia de realizar uma reforma nos organismos de supervisão e controle internacionais, como o Grupo dos Sete (G7) e o Fundo Monetário Internacional (FMI).

A pretensão deste artigo é justamente captar os desafios das relações que a UEM manterá com o exterior. Primeiramente, será tratada a definição de sua complexa política de câmbio em relação aos demais Estados. Adiante, serão abordadas as conseqüências da UEM sobre a participação da Comunidade européia e de seus Estados membros nos organismos internacionais de caráter econômico e financeiro.

Parece oportuno escrevê-lo por ao menos duas razões. De uma parte, a experiência européia é pouco conhecida no Brasil. Seus grandes emblemas, como as instituições supranacionais e, atualmente, o próprio euro, são, freqüentemente, a maior causa de sua incompreensão pois as contradições profundas sob tensão, inerentes ao processo europeu, recusam todo o superficialismo. A repercussão desta experiência sobre o conjunto das relações internacionais também não mereceu a devida atenção da academia, critica dirigida reiteradas vezes à própria Europa.

Por outro lado, quando pululam propostas sobre a adoção de uma moeda única no âmbito do Mercado Comum do Sul (Mercosul), inspiradas por uma reflexão inversamente proporcional à vocação para a mídia, não será inútil a tentativa de mostrar novas facetas de um processo, do qual muitos não vêem mais do que uma bela cédula.

\section{A definição da política de câmbio comunitária}

Elaborar uma política comum de câmbio significa definir a atitude da Comunidade nas suas relações monetárias com o mundo exterior, o que compreende a conclusão de acordos de cooperação monetária e a condução de uma política de 
intervenção sobre os mercados financeiros (venda ou compra de moeda comunitária ou estrangeira).

Desde o começo de sua terceira fase, qual seja a implementação do euro, a UEM provocará importantes repercussões sobre o sistema monetário global. Graças à potência econômica dos Estados que a integram, refletindo um mercado de mais de trezentos milhões de pessoas, é provável que o euro desempenhe um papel relevante como moeda internacional, seja como moeda na qual serão faturados os negócios, seja como moeda de reserva (isto é, ele poderá ser utilizado como referência dos ativos financeiros em escala mundial). Assim, a moeda única poderá vir a ser uma alternativa concreta ao dólar americano.

Para que esta previsão venha a concretizar-se é necessário que a "zona euro" conduza uma efetiva política de câmbio diante das demais moedas. O Tratado de Maastricht, instrumento jurídico criador da UEM, consagra seu artigo 109 a este objetivo. Ele pode ser alcançado desde que sejam resolvidos os potenciais conflitos que podem decorrer do caráter ambíguo de algumas de suas disposições.

\subsection{O mecanismo do artigo 109 do Tratado de Maastricht}

O Tratado de Maastricht reconhece implicitamente que a taxa de câmbio constitui um importante elemento da política monetária e da política econômica. Os três primeiros parágrafos do artigo 109 são dedicados à definição estrutural da política de câmbio, compreendendo duas hipóteses: a conclusão de acordos formais e o sistema de moedas flutuantes, como se pode depreender do quadro infra.

\section{Tabela 2 \\ A política de câmbio}

\begin{tabular}{|l|}
\hline \multicolumn{1}{|c|}{ Art. 109, §1 } \\
conclusão de acordos sobre um sistema de taxa de câmbio \\
para o euro (feita pelo Conselho por unanimidade, a partir \\
de recomendação do BCE ou da Comissão, após consulta \\
do BCE a fim de obter um consenso compatível com a \\
estabilidade de preços) \\
$\begin{array}{l}\text { adoção, modificação ou abandono, pelo Conselho, das } \\
\text { cotações centrais do euro no sistema de taxa de câmbio }\end{array}$ \\
- Prt. 109, §3 \\
ções e à conclusão de acordos previstos no artigo 109, §1, \\
primeira frase \\
(Comissão plenamente associada às negociações, a Comuni- \\
dade deve expressar uma posição única) \\
\hline
\end{tabular}

ou

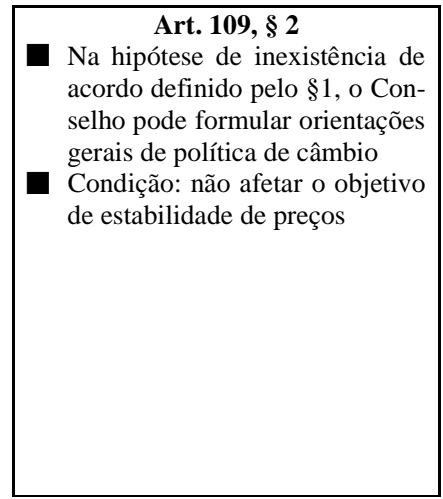

\subsubsection{A conclusão dos acordos de câmbio}

O artigo 109, §§1 e 3, regula a hipótese de associação da Comunidade a terceiros Estados através de acordos monetários. Este dispositivo foi objeto de 
controvérsias ao longo das negociações de Maastricht no que se refere à escolha da autoridade encarregada de elaborar a política de câmbio. As posições da França e da Alemanha foram opostas: a primeira desejava atribuir dita autoridade às instâncias políticas; a segunda preferia investir o Banco Central Europeu (BCE) ${ }^{1}$ desta competência para que, ao realizar sua função principal (a condução da política monetária como um todo), o Banco não fosse vinculado a objetivos de política de câmbio definido por uma instância política. ${ }^{2} \mathrm{O}$ resultado desta divergência é um texto "de compromisso", o que explica a complexidade e a relativa ambigüidade que o caracterizam.

O primeiro parágrafo deste artigo diferencia duas hipóteses: a conclusão de acordos formais referentes a um sistema de taxa de câmbio para o euro diante das moedas não-comunitárias e a faculdade de adotar, modificar ou abandonar as cotações centrais do euro no sistema de taxa de câmbio. Procedimentos diferentes são previstos para as duas situações.

Em primeiro lugar, o dispositivo em questão derroga o artigo 228 do mesmo tratado que fixa o procedimento de conclusão de acordos internacionais pela Comunidade. Segundo o art. 228, a Comissão detém o poder de iniciativa e conduz as negociações do acordo em conformidade com as diretivas que o Conselho estabelece. Após a consulta ao Parlamento europeu, o Conselho decide sobre a conclusão do acordo por maioria qualificada ou, nas hipóteses de acordos de associação (parceiros em posição privilegiada) e de uma disposição expressa do Tratado, por unanimidade.

O procedimento do artigo 109, §1, distancia-se em muito deste esquema geral. Ele prevê que os acordos sobre a taxa de câmbio sejam concluídos pelo Conselho a partir de uma decisão unânime, após a recomendação do BCE ou da Comissão, obrigatória ainda a consulta prévia ao Parlamento europeu. A recomendação do BCE ou do Conselho é inovadora pois, segundo o rito tradicional do art. 228, a Comissão deveria recomendar a abertura das negociações, não a conclusão do acordo. Ocorre que, para a primeira frase deste parágrafo, a consulta ao BCE visa à obtenção de um consenso compatível com o objetivo de estabilidade dos preços, preocupação reiterada em todos os documentos concernentes à UEM. Tal menção é fator de ambigüidade porque o vocábulo consulta parece indicar uma simples manifestação que não vincula juridicamente o Conselho. A palavra consenso, por sua vez, tomada isoladamente, parece indicar uma faculdade de bloquear o processo que seria então atribuída ao BCE. ${ }^{3}$

A segunda frase do mesmo dispositivo prevê a adoção, a modificação ou o abandono das cotações centrais do euro no sistema de taxas de câmbio. O procedimento não é exatamente o mesmo utilizado para a conclusão dos acordos formais supra referidos. O Conselho deverá decidir por maioria qualificada, dispensada a consulta do Parlamento, cujo Presidente deve ser simplesmente informado quanto à decisão. Contudo, a recomendação do BCE ou da Comissão é 
necessária, assim como a consulta ao BCE para que se chegue a um consenso compatível com o objetivo da estabilidade de preços.

O terceiro parágrafo do artigo em questão rege as negociações e a conclusão de acordos sobre as questões relativas ao regime monetário e de câmbio. Aqui o procedimento do artigo 228 é novamente descartado. As negociações devem ocorrer entre a Comunidade e terceiros Estados ou organizações internacionais. O Conselho decide por maioria qualificada depois de feita a recomendação pela Comissão e a consulta do BCE. Da leitura deste artigo resulta a constatação de que o órgão competente para negociar não é expressamente designado. $\mathrm{O}$ texto limita-se a estipular que as negociações devem expressar uma posição única da Comunidade e que a Comissão deve ser plenamente associada às negociações. Deduz-se que a Comissão não dispõe de pleno direito de uma competência para negociar, afinal, ela é simplesmente associada. A condução das negociações parece então estar nas mãos do Conselho que pode constituir a delegação para este fim, mas nada obsta que ele confie à Comissão um mandato que lhe permitiria negociar em nome da Comunidade.

No que tange à exigência de uma posição única da parte da Comunidade, ela parece indicar que a posição manifestada ao longo das negociações deve emanar dos Estados membros. Caberia ao Conselho conduzir as negociações de forma a permitir que os Estados pudessem exprimir uma posição singular e conforme à política comunitária.

Uma última observação diz respeito à conclusão de acordos formais de câmbio. A menção expressa de uma derrogação do artigo 228 está presente nos dois primeiros parágrafos do artigo 109. Especula-se que ele excluiria igualmente o poder consultivo da Corte de Justiça de Luxemburgo. Com efeito, o sexto parágrafo do artigo 228 prevê o procedimento pelo qual a Corte pode ser instada a manifestarse, antes da conclusão de um acordo, no que atine à sua compatibilidade com os tratados constitutivos da Comunidade. Contudo, nada assegura a priori a exclusão desta faculdade de consultar a Corte. Este mecanismo permitiria ao juiz comunitário resolver a questão de repartição de competências entre a Comunidade e os Estados membros para concluir acordos de câmbio. ${ }^{4}$

Percebe-se que ditos parágrafos do artigo 109 prevêem um procedimento sui generis, distinto do artigo 228, e que a posição francesa logrou êxito, uma vez que a competência para concluir os acordos formais foi atribuída ao Conselho.

\subsubsection{As orientações gerais da política de câmbio}

O artigo 109, §2, prevê a hipótese de retorno ao sistema de câmbio fixo, comparável àquele que regulou as relações monetárias internacionais até 1971. Isto não diminui em nada a necessidade de definir uma política de câmbio. Nesta perspectiva, o tratado autoriza o Conselho a formular as orientações gerais da 
política de câmbio diante das demais moedas. O dispositivo visa, em realidade, a coordenação no seio do G7, G5 ou G3. ${ }^{5}$ O Conselho define estas orientações pelo voto por maioria qualificada, sob recomendação da Comissão e após a aprovação do BCE, ou então por recomendação do BCE. Ainda aqui, constata-se que o poder de decisão foi conferido à autoridade política, contrariamente ao que desejava a Alemanha. No entanto, encontra-se novamente o respeito aos objetivos do Sistema Europeu de Bancos Centrais como condição, leia-se estabilidade de preços. Mais adiante, tratar-se-á dos detalhes que foram trazidos ao tema pelo Conselho Europeu de Luxemburgo, de dezembro de 1997.

\subsubsection{A execução da política de câmbio}

Se a definição da política de câmbio cabe ao Conselho, sua execução compete ao BCE. O artigo 3, §1, do estatuto do Sistema Europeu de Bancos Centrais (SEBC) remete ao artigo 105, §2, do Tratado de Maastricht para indicar as principais missões do Sistema: conduzir as operações de câmbio em conformidade ao artigo 109, além de reter e administrar as reservas de câmbio oficiais dos Estados membros. Num primeiro momento, o BCE é dotado pelos Bancos Centrais nacionais de reservas de câmbio até o limite de 50 bilhões de euros. Tais reservas não incluem as moedas dos Estados membros, os euros, tampouco as reservas junto ao FMI. Reservas suplementares podem ser utilizadas pelo BCE nos limites e condições fixados pelo Conselho. Deduz-se que não há transferência de propriedade das reservas ao BCE, mas ele de fato as têm à sua inteira disposição.

Os Bancos Centrais nacionais conservam algumas reservas cuja utilização será submetida à autorização do BCE, com o escopo de assegurar a coerência deste gesto em relação às políticas de câmbio e monetária da Comunidade (artigo 31 do Estatuto).

\subsection{Os potenciais conflitos}

A política de câmbio, tal como é concebida pelo artigo 109, poderá criar um certo número de conflitos. Dois tipos de dificuldades afiguram-se: a ameaça à independência do BCE e o conflito de competências entre a Comunidade e os Estados Membros, o que será estudado através do exemplo da zona franco, o largo espaço territorial onde se utiliza atualmente a moeda francesa.

\subsubsection{A independência do BCE}

Os Estatutos do SEBC determinam que o BCE e os Bancos Centrais nacionais não podem solicitar ou aceitar instruções das instituições comunitárias e dos governos dos Estados membros (artigo 7). Os últimos comprometem-se a 
evitar uma possível influência sobre a BCE e seus próprios Bancos Centrais. O artigo 105, §2, do Tratado de Maastricht confia ao SEBC a definição e a execução da política monetária da Comunidade, a condução das operações de câmbio consoante ao artigo 109, assim como a posse e a gestão das reservas oficiais de câmbio dos Estados membros.

Quando da negociação do Tratado em tela, a Alemanha temia que a definição da política de câmbio pelo Conselho tivesse por conseqüência a perda da independência do BCE, este responsável pela execução da política definida pelo Conselho. Logo, haveria o risco de que tal execução viesse a comprometer o objetivo da estabilidade de preços. Num sistema de câmbio estável, os Estados tem a obrigação de sustentar as moedas estrangeiras vendendo sua própria moeda contra a moeda estrangeira em questão. Para manter a paridade, os Estados devem aumentar em certos momentos sua massa monetária, o que de fato pode constituir uma ameaça para a estabilidade de preços do ponto de vista interno. A UEM apresenta uma contradição estrutural neste aspecto. ${ }^{6}$ Por um lado, ela busca a estabilidade de preços pela estabilização dos câmbios internos mas, de outra parte, ela se permite participar aos sistemas de câmbio fixo externos, o que pode levar a uma instabilidade de preços. Por esta razão, a política de câmbio prevista pelo artigo 109 foi estritamente demarcada e o BCE nela desempenha um papel muito importante.

Para compreender a influência do BCE na definição da política de câmbio, convém lembrar o texto do artigo 109: a competência do Conselho é visivelmente limitada pela obrigação de compatibilidade com o objetivo principal de assegurar a estabilidade de preços. A Comissão européia ${ }^{7}$ observa que o artigo 109, §1, não obriga o Conselho e o BCE a chegar a um acordo, mas simplesmente a concertar suas posições. Em caso de divergência, prevalece a opinião do Conselho. Inobstante, o risco de desacordo profundo é modesto pois o Conselho é obrigado a respeitar incondicionalmente o objetivo de estabilidade de preços em matéria de política de câmbio.

As orientações gerais do Conselho, não possuem valor jurídico obrigatório neste domínio. ${ }^{8} \mathrm{O}$ artigo 105, §2, prevê apenas que o BCE deve conduzir as operações de câmbio de acordo com o artigo 109. As conclusões do Conselho Europeu de Luxemburgo, já citado, são muito reveladores neste aspecto. Elas precisam que, no que se refere à execução da política de câmbio, as orientações gerais do Conselho diante de uma ou diversas moedas não-comunitárias serão formuladas apenas em circunstâncias excepcionais, à luz dos princípios e políticas definidos pelo Tratado. Na ausência destas orientações, o BCE deve assumir a direção da política de câmbio.

O retorno a um sistema de câmbio fixo, previsto pelo artigo 109, §1, é pouco provável. Na ausência dele, o Conselho fixa simples orientações gerais não obrigatórias para o BCE, e, isto, à título excepcional. Logo, não há razão para 
temer que as competências atribuídas à autoridade política possam ameaçar a estabilidade de preços, objetivo consagrado pelo próprio artigo 3 A do Tratado de Maastricht.

\subsubsection{A repartição de competências entre a Comunidade e os Estados membros}

A competência da Comunidade em matéria de câmbio é exclusiva ou os Estados membros conservam uma espécie de competência residual ? Para melhor responder a esta questão, o exemplo da zona franco pode ser útil. Criada em 1939, ela foi de início apenas um mecanismo interno entre a França e suas colônias. Com a independência destas, a zona franco tornou-se uma verdadeira organização monetária trans-regional onde um grupo de países é ligado a um país dominante no que se refere à moeda, no caso a moeda francesa. A organização compreende quatorze Estados africanos e as coletividades territoriais de Mayotte e Mônaco e, enquanto zona monetária, ela constitui um sistema de câmbio. ${ }^{9}$ As moedas de seus países membros são conversíveis em francos franceses de forma ilimitada, a partir de paridades fixas.

Cada Estado integrante desta zona é titular de uma conta de operações aberta junto ao Tesouro francês, na qual ele deposita o essencial de suas disponibilidades monetárias. Essas reservas em francos dispõem de uma garantia de câmbio em moeda estrangeira no caso de depreciação do franco francês em relação ao direito especial de saque. ${ }^{10}$

A zona franco tende à se transformar. Quando da reunião dos Ministros de Finanças dos Estados membros (Ouagadougou, abril de 1991), houve um compromisso expresso no sentido de construir uma verdadeira união econômica que resultaria ao cabo em um mercado comum. A zona franco é, por vezes, percebida como um instrumento concreto de solidariedade entre o Norte e o Sul.

A análise do funcionamento da zona franco demonstra que ela diz respeito à política de câmbio. Ora, no âmbito da UEM esta política compete ao Conselho e ao BCE. Considerando que se trata de uma competência exclusiva, a zona franco deveria desaparecer ou ser substituída por uma "zona euro". Caso seja aceita a tese de que os Estados membros da UEM possuem uma competência residual, a França poderia então manter esta relação particular com certos Estados. A resposta a esta questão é incerta, devendo ser considerada ainda a possibilidade de uma exceção a ser admitida pela Comunidade diante da peculiaridade francesa.

Muitos protocolos e declarações anexas ao Tratado de Maastricht propõemse a resolver algumas das relações monetárias exteriores próprias a diversos Estados membros da Comunidade. Existe, por exemplo, um Protocolo sobre a França que lhe permite conservar o privilégio de emissão de moeda nos territórios de alémmar e determinar a paridade do franco CFP. Existe, igualmente, uma declaração relativa a San Marino e ao Vaticano, na qual mantêm-se as relações monetárias entre estas entidades e a Itália até a vigência completa do euro. 
O fato de que nenhum protocolo foi dedicado à zona franco é interpretado por alguns como uma confirmação de que a Comunidade será competente para definir a natureza das relações que ela manterá com os membros deste espaço monetário após a implementação acabada do euro. ${ }^{11}$ Para outros, a zona franco compreende apenas compromissos do Tesouro francês, e não do Banco Central, quanto a terceiros Estados, o que afastaria a incidência da união monetária sobre um tal regime. De outra parte, o quinto parágrafo do artigo $109^{12}$ será provavelmente usado pela França como uma espécie de salvaguarda de sua competência.

\section{As conseqüências da UEM sobre a participação da Comunidade nas organizações internacionais}

\subsection{As competências comunitárias em matéria de participação e representação na esfera internacional}

O artigo 109, §4, do Tratado de Maastricht determina um só procedimento mas diferentes modalidades de voto quando se trata de decidir sobre a participação ou a representação da Comunidade nos foros internacionais que atuam nos domínios cobertos pela UEM.

A noção de participação corresponde à posição que a Comunidade ocupa em nível internacional no que se refere às questões de particular interesse para a UEM. O Conselho deve, então, definir o estatuto da Comunidade no seio de uma entidade internacional através do voto por maioria qualificada. Vale lembrar aqui o parágrafo quinto do mesmo artigo, que assegura aos Estados membros a possibilidade de negociar nas instâncias internacionais e concluir acordos internacionais no âmbito da UEM.

De outra parte, quando a decisão atine à representação, ou seja, à identificação do sujeito, na esfera comunitária, que deve ser titular das competências inerentes à representação, o Conselho vota por unanimidade e deve respeitar a repartição de competências estabelecida pelos artigos 103 e 105 do Tratado. A partir desta dicotomia, tratar-se-á, primeiramente, a jurisprudência comunitária referente à divisão de competências entre Estados membros e a Comunidade para, em seguida, compreender o dilema inter-institucional de repartição das competências em âmbito internacional.

\subsubsection{A jurisprudência comunitária e a repartição de competências entre os Estados membros e a Comunidade}

Para Jean-Victor Louis, o interesse em distinguir as noções de participação e de representação reside precisamente na idéia de que a participação da Comunidade européia no FMI, por exemplo, não significaria necessariamente a 
eliminação dos representantes dos governos nacionais no interior deste foro. ${ }^{13}$ Esta convicção serve como indicativo do quão polêmico é o tema, merecedor de uma particular evolução jurisprudencial.

Na década de 70, a Corte de Justiça estabeleceu um princípio que se tornou célebre, através do caso AETR. ${ }^{14}$ Segundo a Corte, cada vez que, para a execução de uma política comum prevista pelo Tratado, a Comunidade instaurar regras comuns, sob qualquer forma que seja, os Estados membros não mais possuem o direito de contratar com terceiros obrigações que afetem esta regra, que o façam individual ou coletivamente. O juiz comunitário determina ainda que não se pode, na realização das disposições do tratado, separar o regime de medidas internas à Comunidade do regime das relações exteriores que ela mantém.

A sentença AETR inaugura a lógica segundo a qual a competência externa da Comunidade pode ser deduzida de suas competências internas, raciocínio conhecido como teoria do paralelismo in foro interno/ in foro externo. Porém, a decisão AETR foi interpretada no sentido de que uma competência externa só pode ser deduzida do exercício efetivo de uma competência interna através da adoção de regras comuns.

Em algumas decisões que seguiram-se à AETR, a Corte suprimiu esta condição, considerando que a Comunidade tem competência para assumir compromissos internacionais necessários à realização de um objetivo estipulado no plano interno, mesmo em ausência de uma disposição expressa a esse respeito. ${ }^{15}$ Segundo Joël Rideau, o princípio de alinhamento das competências externas em relação às competências internas foi retomado e ampliado pela jurisprudência posterior de Luxemburgo. ${ }^{16}$

Esta visão mais ampla encontrou seu fim no Parecer 1/94, de 15 de novembro de 1994, relativo à conclusão dos acordos que constituíram a Organização Mundial do Comércio, seguido pelo Parecer 2/92, de 24 de março de 95, referente à participação da Comunidade na OCDE. Reduz-se a visão da jurisprudência AETR, afirmando que o paralelismo em questão é subordinado à presença de atos normativos internos nos domínios visados pelo acordo em questão. O Parecer 1/94 assegura o direito dos Estados membros de contratar obrigações com terceiros Estados, seja individual ou coletivamente. Ele sustenta literalmente que a competência da Comunidade torna-se exclusiva num dado domínio tão somente na medida em que regras comuns foram estabelecidas no plano interno.

O mesmo Parecer menciona a obrigação de cooperação entre os Estados membros e as instituições comunitárias que decorre da necessária unidade de representação internacional da Comunidade. No entanto, ele não define nem o fundamento nem o conteúdo desta obrigação. Para Denys Simon, a ausência de indicação precisa nestes recentes pareceres a respeito dos titulares das competências repartidas entre Comunidade e Estados membros, enseja o forte risco de que se formem competências concorrentes no sentido formal do termo. Criar-se-á uma confusão lamentável no momento da execução dos compromissos internacionais 
de ambos os sujeitos, a tal ponto que o contencioso suscetível de ser acionado resolverá tardia ou imperfeitamente os litígios, impondo um custo político muito elevado à Comunidade. ${ }^{17}$

O parágrafo quinto do artigo 109 em nada contribui ao esclarecimento da confusão em tela no âmbito da UEM. Ele confere aos Estados o poder de negociar nas instâncias internacionais e de concluir acordos, embora reconheça a competência e os compromissos comunitários. Pode-se compreender esta disposição como uma garantia, para os Estados membros, de que a Comunidade não vai substituí-los no seio das instituições econômicas internacionais, ainda que ela assuma paulatinamente novas competências.

\subsubsection{O dilema inter-institucional de repartição de competências}

A política monetária tornou-se uma competência exclusiva da Comunidade, gerada pelo SEBC. Mas a política econômica resta dividida entre os Estados e a Comunidade, sob a coordenação do Conselho e sob a supervisão da Comissão. Os artigos 103 e 105 do Tratado, expressamente mencionados pelo artigo 109, §4, estabelecem uma assimetria pela qual não se poderá jamais constatar um efeito de substituição em matéria de política econômica.

Existem diversas proposições a este respeito, a maior parte delas no sentido de que a política econômica e monetária deve ser objeto de uma modalidade mista de participação na esfera internacional, compreendendo os Estados e a Comunidade. Mas persiste a questão de definir quem representará a Comunidade, diante dos critérios de repartição de competências internas que atribui diferentes pesos ao Conselho, ao BCE e à Comissão.

Quanto à política monetária, há uma certa fricção entre o parágrafo quarto do artigo 109 e o artigo 6 dos Estatutos do SEBC e do BCE, sendo o último dedicado à cooperação internacional na área de competência do SEBC. Ele estipula que compete ao BCE decidir a maneira pela qual o SEBC será representado e que o Banco está habilitado a participar das instituições monetárias internacionais. Os bancos nacionais podem igualmente participar, com a ressalva de que o BCE deve autorizar dita participação. Ora, o artigo 109, §4, reservou ao BCE um papel apenas consultivo na definição da representação externa da Comunidade. Mas o artigo 6 dos Estatutos salienta que sua aplicação deve ocorrer sem prejuízo do artigo $109, \S 4 \ldots$

As conclusões do Conselho europeu de Luxemburgo são tímidas diante dos dilemas acima descritos. O Conselho e o BCE devem, segundo o Conselho europeu, desempenhar suas funções no que atine à representação internacional da Comunidade de forma eficaz e respeitando a repartição de competências prevista pelo Tratado. A Comissão será associada à representação externa no que for necessário para que possa desempenhar o papel que lhe atribuem as disposições dos tratados. ${ }^{18}$ 
Em seguida, o Conselho apela para um diálogo contínuo e frutífero entre o Conselho e o BCE, respeitando a independência do segundo, como um elemento importante do bom funcionamento da UEM.

A incerteza a respeito dos titulares da representação externa da Comunidade impregna os debates em curso sobre as reformas que parecem necessárias no âmbito das instituições econômicas internacionais face à realidade de uma moeda única européia.

\subsection{As conseqüências da UEM para as mais importantes instituições econômicas internacionais}

\subsubsection{O Fundo Monetário Internacional}

\section{Tabela 3 \\ O FMI}

\begin{tabular}{|c|c|c|}
\hline Definição & \multicolumn{2}{|l|}{ - autoridade de consulta e coordenação } \\
\hline Origem & \multicolumn{2}{|c|}{$\begin{array}{l}\text { - Acordos de Bretton Woods, julho de } 1944 \\
\text { - Uma nova dimensão : Acordos de Kingston ou da Jamaica, } 1976\end{array}$} \\
\hline Função & \multicolumn{2}{|c|}{$\begin{array}{l}\text { - Código de boa conduta monetária (poderes moral, semi-regulamentar, } \\
\text { semi-judiciário e de auto-interpretação) } \\
\text { - Livre conversibilidade de moedas (exceção artigo XIV Estatutos e } \\
\text { derrogação expressa) }\end{array}$} \\
\hline Orgão & Composição & Competência \\
\hline $\begin{array}{l}\text { Conselho de governadores } \\
\text { (órgão dirigente) }\end{array}$ & $\begin{array}{l}\text { Ministros de finanças ou Presidentes } \\
\text { dos Bancos centrais }\end{array}$ & $\begin{array}{l}\text { - Admissão de novos Estados } \\
\text { membros } \\
\text { - Revisão de quotas } \\
\text { - Decisão de expulsão, etc. }\end{array}$ \\
\hline $\begin{array}{l}\text { Comitê interino } \\
\text { (órgão político) }\end{array}$ & $\begin{array}{l}\text { Os } 5 \text { países dos quais as quotas são } \\
\text { mais importantes têm um } \\
\text { administrador permanente } \\
\text { (Alemanha, Estados Unidos, França, } \\
\text { Japão e Reino Unido) } \\
+\quad \text { Arábia Saudita }+18 \\
\text { administradores eleitos }\end{array}$ & $\begin{array}{l}\text { Aplicação de medidas destinadas a } \\
\text { auxiliar os países em } \\
\text { desenvolvimento }\end{array}$ \\
\hline $\begin{array}{l}\text { O Conselho de } \\
\text { administração } \\
\text { (órgão dirigente) }\end{array}$ & $\begin{array}{l}\text { - Os } 5 \\
\text { - } 3 \text { países nomeados de fato (Arábia } \\
\text { Saudita, China e Rússia) } \\
\text { - } 19 \text { eleitos por grupos de países } \\
\text { constituídos pelos outros países } \\
\text { membros (mandato de } 2 \text { anos) }\end{array}$ & $\begin{array}{l}\text { - gestão do Fundo (órgão restrito) } \\
\text { - eleição do Diretor gerente }\end{array}$ \\
\hline Meios de fi & \multicolumn{2}{|c|}{$\begin{array}{l}\text { - Quotas-parte (subscrição no pool de divisas, negociado com o FMI a cada } \\
\text { candidatura, revisado periodicamente) } \\
\text { - A remuneração de investimentos e comissões } \\
\text { - Empréstimos (do próprio FMI ou de grupos de Estados) }\end{array}$} \\
\hline $\begin{array}{c}\text { Modalidades de } \\
\text { Assistência financeira } \\
\text { oferecida }\end{array}$ & \multicolumn{2}{|c|}{$\begin{array}{l}\text { - Compra ou saque - incondicional (até } 100 \% \text { da quota-parte) } \\
\text { - As parcelas de crédito (sucessivas)- condicional (até } 200 \% \text { da quota-parte) } \\
\text { - Políticas especificas - condicional ( parcela de crédito + políticas } \\
\text { especificas = até } 450 \% \text { da quota-parte) }\end{array}$} \\
\hline DES & \multicolumn{2}{|c|}{$\begin{array}{l}\text { Direitos Especiais de Saque - moeda escritural fixada em função de uma } \\
\text { cesta de cinco moedas (Alemanha, Estados Unidos, França, Japão e Reino } \\
\text { Unido) }\end{array}$} \\
\hline
\end{tabular}


Os membros do FMI são países que dispõe de sua própria moeda e uma quota-parte individual no Fundo. Há uma discussão sobre a existência ou não de casos precedentes de uniões monetárias no seio do FMI. Seguidamente, evoca-se a União econômica entre Bélgica e Luxemburgo ou mesmo a zona franco. Mas a maior parte dos autores, sejam economistas ou juristas, reconhece que jamais um grupo de países da importância dos membros da Comunidade européia dotou-se de uma só moeda. Ninguém duvida de que uma decisão, da parte da Comunidade, de vir a ser um só membro do FMI tornaria indispensável a reforma dos estatutos da instituição. ${ }^{19}$ Inobstante, para Philippe Maystadt, Presidente do Comitê interino do FMI para os países da União européia, toda decisão de constituir um só membro, dotado de uma só quota-parte, implicará uma perda de soberania para os Estados. ${ }^{20}$

Mesmo não admitida a constituição de um só membro, a UEM é um fato e como tal deve ser tomada em consideração no sistema de supervisão monetária e de câmbio do Fundo. As consultas bilaterais devem se estender além dos Estados membros para chegar às instituições comunitárias. Pode-se questionar acerca de quem representará a UEM nas reuniões do Conselho de Administração do FMI: o BCE ou o ECOFIN ? A mesma interrogação vale para a eleição de administradores e para a participação da Comunidade nas constituintes.

De outra parte, o DES é calculado atualmente em relação às cinco moedas dos primeiros exportadores mundiais de bens e serviços, dos quais três são europeus (marco alemão, franco francês e libra esterlina), logo ao menos dois desaparecerão. A utilização do euro neste cálculo exige mudanças de princípio e também de avaliação.

Enfim, pode-se reconhecer aos países da UEM um direito de acesso aos recursos do Fundo? No caso de uma resposta negativa, admite-se uma violação dos direitos dos membros do FMI e do princípio fundamental de uniformidade em seu tratamento. A probabilidade de utilização de créditos pelos Estados europeus é discutível, mas é preciso reconhecer que o impacto do euro sobre o mercado pode implicar o acesso a reservas para responder a ataques especulativos, uma vez que no quadro da UEM não mais será possível outorgar auxílios de balança de pagamentos.

Porém, se a resposta for positiva, coloca-se o problema de saber em que medida o Fundo pode oferecer sua ajuda ao conjunto da zona se a UEM não pode tornar-se membro da instituição.

\subsubsection{O Grupo dos Cinco e o Grupo dos Sete}

A participação da Comunidade no G7 e no G5 enseja um outro tipo de problema devido à natureza destes órgãos de concertação. Trata-se de instâncias onde não são tomadas decisões formais, mas se presume que as discussões e conclusões delas oriundas traduzir-se-ão em posições tomadas por cada membro nas diferentes instâncias onde seu país tem voz. 


\section{Tabela 4 \\ O G7}

\begin{tabular}{|c|l|}
\hline Definição & $\begin{array}{l}\text { - Foro de origem espontânea, sem mandato preciso, organização ou } \\
\text { secretariado estruturados } \\
\text { - Suas reuniões são preparadas pelos sherpas (representantes pessoais dos } \\
\text { Chefes de Estado ou de Governo) }\end{array}$ \\
\hline Composição & $\begin{array}{l}\text { - Os cinco países cujas moedas são incluídas na definição do DES + Itália + } \\
\text { Canada } \\
\text { - Diferentes formações, as mais importantes Chefes de Estado e Ministros } \\
\text { das Finanças } \\
\text { - Os Presidentes da União Européia e da Comissão são convidados como } \\
\text { observadores, assim como a Rússia }\end{array}$ \\
\hline Domínios de discussão \\
G7 Finanças & $\begin{array}{l}\text { - Política de câmbio } \\
\text { - Política monetária } \\
\text { - Política econômica e orçamentária }\end{array}$ \\
\hline
\end{tabular}

Ora, o artigo 103 do Tratado de Maastricht determina de uma forma límpida que o lugar de coordenação das políticas econômicas dos Estados Membros é o Conselho. Parece evidente que o espírito do Tratado é incompatível com a simples transposição das políticas negociadas internacionalmente no âmbito comunitário.

De outra parte, tratando-se da representação da Comunidade, ouve-se falar de uma substituição do G7 por um G3 pois certos membros do G7 deixarão de ser responsáveis pela sua política monetária. Todavia, a política orçamentária continuará a depender das autoridades nacionais, o que leva a pensar que um G3 poderia existir apenas para as questões monetárias.

Resta ainda a definir se a delegação européia deverá representar todos os membros da Comunidade ou apenas os participantes da UEM. Pode-se mencionar exemplos incômodos como a Holanda, que participa da UEM, então faria parte do mencionado G3, mas não é membro do G7. Já o Reino Unido participa do G7 mas não integra a UEM.

Se o Conselho é, em princípio, habilitado a representar a Comunidade nas reuniões de coordenação internacional, pode acontecer que, em algumas oportunidades, o Presidente do Conselho seja Ministro de um país não membro da UEM, devido à rotatividade da presidência deste órgão a cada seis meses.

Enfim, a não coincidência do G7 e do G3 de uma parte, e da Comunidade e da UEM de outra parte, pode significar uma falta de continuidade ou um problema de legitimidade para a Europa, complicando a coordenação internacional no domínio econômico e monetário, assim como o próprio funcionamento da UEM. 


\section{Bibliografia}

Obras genéricas

BELANGER, Michel. Institutions économiques internationales. Paris: Economica, 97, spéc. "La structuration du système monétaire et financier mondial”, Segunda parte, Título I, Capítulo primeiro, pp. 100-121.

LOUIS, Jean-Victor. L'Union économique et monétaire, Commentaire Jacques MEGRET, Vol. 6. Bruxelles: ULB, 1995.

MANIN, Philippe. Les Communautés européennes - L'Union européenne. Paris: Pedone, 1997, part. pp. 115-127 e 145-152.

NGUYEN QUOC DINH. Droit international publique. Paris: LGDJ, 1994, spéc. "Relations monétaires et financières”, Terceira parte, Título II, Capítulo II, pp. 995-1006.

REY, Jean-Jacques; ROBERT, Eric. Institutions économiques internationales. Bruxelles: Bruylant, 1997, part. pp. 36-38 et 130-133.

Artigos especializados

BENASSY-QUERE, Agnes. "L'euro dans le système monétaire international”. Cahiers français $\mathrm{n}^{\circ}$ 282, julho-setembro 1997.

CARREAU, Dominique. "La communauté économique européenne face aux problèmes monétaires”. RTDE, Número 3-4, julho-setembro 1971.

DEHOUSSE, Franklin; GHEMAR, Katelyne. Le traité de Maastricht et les relations extérieures de la Communauté européenne. Journal européen de droit international, 1994/2, p.151.

LAGAYETTE, Philippe. "Histoire du G7: ambitions et bilan”. in Les enjeux du G7. Paris: Economica, 1997, p. 13.

LOUIS, Jean-Victor. “Union monétaire et Fonds monétaire international”. Mélanges Hahm, p.201.

MANIN, Philippe. “A propos de l'accord instituant l'OMC et de l'accord sur les marchés publics: la question de l'invocabilité des accords internationaux conclus par la CE”. RTDE 33 (3), julho-setembro 1997, p. 399-428.

SIMON, Denys. "La compétence de la Communauté pour conclure l'accord OMC: l'avis 1/94 de la Cour de Justice”. Europe, dezembro 1994.

\section{Documentos}

Corte de Justiça das Comunidades Européias (CJCE). Avis 1/94. 15 novembro 1994, R. I-5267. 
CJCE. Commission c/ Conseil (A.E.T.R.). Aff. 22/70, 31 março 1971, R.263. Comissão Européia. Les aspects externes de l'Union économique et monétaire. Bulletin Agence Europe, Número 2034, 8 maio 1997.

Conselho europeu. Union économique et monétaire. in Bull. EU 12-1997.

Fundo monetário internacional. Les conséquences de l'UEM pour l'Europe et l'économie mondiale. FMI Bulletin, Vol. 26, Numero 7, 14 abril 1997. Fonds Monétaire International. Working Paper, The CFA Franc Zone and the MEU. Novembre 1997.

\section{Notas}

1 Para melhor compreender o funcionamento da UEM, um compêndio de toda a legislação atinente é acessível via Internet ( http://www.ecu-activities.be/compendium/fr/index.html ). Ver especialmente os estatutos do SEBC e do BCE no site (http://www.ecu-activities.be/ compendium/fr/92sebcf.html).

Ver LOUIS, Jean-Victor. L'Union économique et monétaire. in Commentaire Jacques Megret, Volume 6. Bruxelas: Universidade Livre de Bruxelas, 1995, p. 82.

3 Conforme F. Dehousse e K. Ghemar in Le Traité de Maastricht et les relations extérieures de la Communauté européenne. Jornal de Direito Internacional, 1994/2, p. 156.

$4 \quad$ Ver adiante o item 1.2.2.

5 Por exemplo, os chamados “acordos do Louvre”. Para compreender em que consiste o G7, ver adiante o item 2.2.2.

6 Conforme Dehousee, op. cit., p. 154.

7 Op. cit.

8 Conforme J.-V. Louis, op. cit., p.84.

9 Segundo M. Belanger. Les institutions économiques internationales. Paris: Economica, 1997, p.118.

10 Ver adiante o conceito de Direito especial de saque no item 2.2.1.

11 Ver Fundo Monetário Internacional. Documento de Trabalho, The CFA Franc Zone and the MEU. novembro de 1997.

12 Ver em seguida, item 2.1.1.

13 in “Union monétaire et Fonds monétaire international”. Mélanges Hahm, p. 212.

14 Acordo europeu relativo aos equipamentos de veículos que efetuam transporte rodoviário internacional, processo 22/70, decisão de 31 de março de 1971, Reccueil p. 263.

15 Ver Parecer 1/76, de 24/4/77 e decisão Kramer, CJCE 14/7/76.

16 In "Les accords internationaux dans la jurisprudence de la Cour”. Revue Géneral du Droit International Public, abril-junho 1990, p. 299.

17 In “La compétence de la Communauté pour conclure l'Accord OMC”. Revue Europe, dezembro de 1994, p.4.

18 Ver Boletim EU 12-1997, p. 13.

19 Ver A. Bénassy-Quéré. “L’euro dans le système monétaire international”. Cahiers Français, julho-setembro 1997.

20 In Boletim do FMI, Volume 26, Número 7, 14/4/97, p.104. 
Resumo

O texto analisa os aspectos político, jurídico e institucional da construção da União Econômica e Monetária européia, do euro, e seu impacto nas formações de políticas econômicas nos Estados membros.

\section{Abstract}

The article analyses the political, juridical and institutional aspects of the building up of the Monetary and Economic European Union, the euro, and its impact on the member states economic policy formation.

Palavras-chave: União Econômica e Monetária européia. Euro. Política econômica. Key-words: Monetary and Economic European Union. Euro. Economic policy. 